\title{
Optimized plasma-polymerized fluoropolymer mask for local porous silicon formation
}

Bin Lu’, Thomas Defforge, Bálint Fodor, Benjamin Morillon, Daniel Alquier, and Gaël Gautier

Citation: J. Appl. Phys. 119, 213301 (2016); doi: 10.1063/1.4953088

View online: http://dx.doi.org/10.1063/1.4953088

View Table of Contents: http://aip.scitation.org/toc/jap/119/21

Published by the American Institute of Physics 


\title{
Optimized plasma-polymerized fluoropolymer mask for local porous silicon formation
}

\author{
Bin Lu, ${ }^{1, a)}$ Thomas Defforge, ${ }^{1}$ Bálint Fodor, ${ }^{1,2}$ Benjamin Morillon, ${ }^{3}$ Daniel Alquier, ${ }^{1}$ \\ and Gaël Gautier ${ }^{1}$ \\ ${ }^{1}$ Université François Rabelais de Tours, GREMAN, CNRS-UMR7347, INSA-CVL, 16 Rue Pierre et Marie \\ Curie, BP 7155,37071 Tours Cedex 2, France \\ ${ }^{2}$ Institute for Technical Physics and Materials Science, Centre for Energy Research, Hungarian Academy \\ of Sciences, Konkoly Thege Miklós út 29-33, H-1121 Budapest, Hungary \\ ${ }^{3}$ STMicroelectronics, 10 Rue Thalès de Milet CS 97155, 37071 Tours Cedex 2, France
}

(Received 12 April 2016; accepted 18 May 2016; published online 3 June 2016)

\begin{abstract}
Mass production of hybrid silicon/porous silicon substrates requires a simple, low-cost, and reliable patterning process to locally form porous regions on silicon wafers. An innovative masking technology based on plasma-polymerized fluoropolymer (PPFP) has been proposed as a promising candidate. However, the use of PPFP film on silicon substrate requires an adhesion promoter which may cause several side effects, including film peeling-off and pinhole formation. This work aims to improve the adhesion strength without using the adhesion promoter. The present study shows that, by adopting a hydrogen-terminated surface and an optimized gas precursor composition of 25/25 sccm $\mathrm{CHF}_{3} / \mathrm{C}_{2} \mathrm{H}_{4}$, good adhesion of PPFP to silicon is obtained before and during porous silicon formation. PPFP mask deposited at high pressure shows well-defined borders after anodization. Finally, an optimized PPFP-based patterning process is proposed. Published by AIP Publishing.

[http://dx.doi.org/10.1063/1.4953088]
\end{abstract}

\section{INTRODUCTION}

Production of high quality porous silicon (PS), by electrochemical anodization, is important to further extend the functionality of silicon technologies. ${ }^{1,2}$ Owing to its remarkable properties such as high surface to volume ratio, size controllability, insulation, and biocompatibility, numerous applications based on well-engineered PS have been demonstrated in many different fields, ${ }^{3}$ including microelectronics, bioengineering, medicine, chemical sensing, etc. However, for many of the above mentioned applications, it is essential to form PS in predefined regions. ${ }^{4-11}$ Synthesis of patterned PS is usually achieved by masking a silicon substrate with a layer of etching resistant material. ${ }^{12}$

For a short-duration anodic etching, conventional masking layers, such as photoresist ${ }^{13}$ and silicon dioxide, ${ }^{14}$ are quite convenient, and the corresponding masking procedures are well mastered in the semiconductor industry. However, for a long-duration anodic etching (up to several hours), only a few materials can survive in HF-based etching environment. In the literature, different kinds of HF resistant materials have been tested and proposed as a masking layer for deep PS formation. ${ }^{13-28}$ Among them, silicon nitride $\left(\mathrm{Si}_{\mathrm{x}} \mathrm{N}_{\mathrm{y}}\right),{ }^{15,16}$ bilayer of polycrystalline silicon/silicon dioxide, ${ }^{18,22}$ or tri-layer stack of poly- $\mathrm{Si} / \mathrm{Si}_{\mathrm{x}} \mathrm{N}_{\mathrm{y}} / \mathrm{SiO}_{2}{ }^{12}$ are the most widely used masking materials due to the maturities of deposition techniques and the compatibility with current silicon processing. However, the common drawback of all these masking materials is the complicated post-etching mask removal procedures when bare silicon surface is ultimately required. ${ }^{12}$

\footnotetext{
${ }^{\text {a) }}$ Author to whom correspondence should be addressed. Electronic mail: bin.lu@univ-tours.fr.
}

Plasma-polymerized fluoropolymer (PPFP) is a group of functional polymer materials synthesized via glow discharges, which can be easily coated on various substrates with different dimensions and morphologies. ${ }^{29}$ By carefully choosing gas monomer and kinetic formation parameters such as RF power input, gas pressure, etc., it is, indeed, possible to synthesize PPFP with desired characteristics. ${ }^{29}$ The recent work by Defforge et $a l .^{27}$ has indicated that, by cosynthesizing trifluoromethane $\left(\mathrm{CHF}_{3}\right)$ and ethylene $\left(\mathrm{C}_{2} \mathrm{H}_{4}\right)$, PPFP with excellent HF resistance is deposited on silicon wafers. As an organic material, this film enables a rapid $\mathrm{O}_{2}$ plasma removal with a minor damage on the PS layer (nearsurface oxidation). Consequently, the PPFP has been proposed as a promising material for PS patterning. However, the successful application of this material for PS masking has to overcome some important challenges, including its poor adhesion to the silicon substrate during anodic etching.

The intension of improving the adhesion of similar fluoropolymer to the silicon substrate has attracted considerable research interest for many years. In general, two methods have been proposed in the literature: (i) an adhesion promoter $^{30}$ and/or (ii) a surface-activated substrate. ${ }^{31,32}$ The former method was used in previous experiments described in Ref. 27. A thin hydrocarbon layer was pre-deposited on the silicon substrate by introducing $\mathrm{C}_{2} \mathrm{H}_{4}$ plasma before PPFP synthesis. This layer resulted in high adhesion strength between PPFP and silicon during the deposition process and later anodic etching. However, the use of this plasmapolymerized adhesion promoter may be accompanied by several side effects.

As indicated by Niinomi et al. ${ }^{33}$ in addition to the film, plasma-polymerization of $\mathrm{C}_{2} \mathrm{H}_{4}$ may lead to other form of final products, e.g., amorphous polymer powder. Fig. 1 presents an 


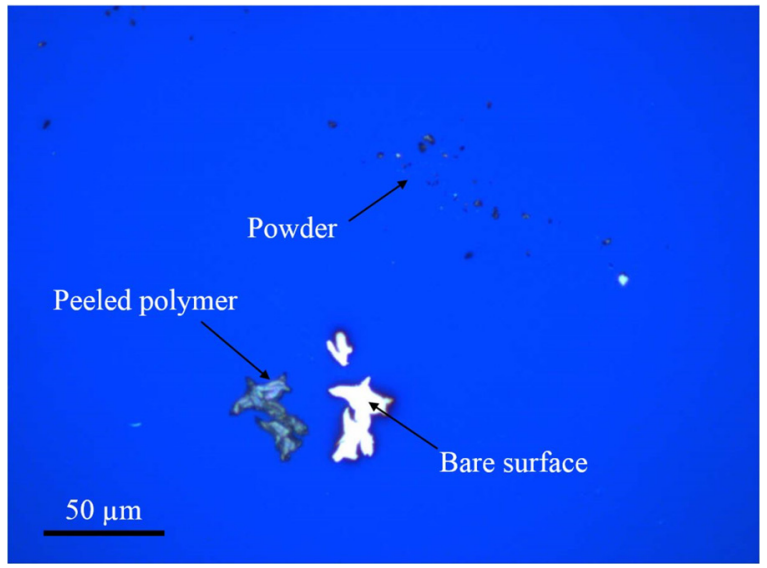

FIG. 1. Surface morphology of plasma-polymerized $\mathrm{C}_{2} \mathrm{H}_{4}$.

example of such unintentionally formed structure. After $1 \mathrm{~min}$ deposition in ethylene plasma, apart from a dark blue film, particles can be randomly observed on the silicon surface. Additionally, some sheets of polymer film were detached from the parent substrate, leaving unprotected spots at the surface. If PPFP synthesis is subsequently performed upon this inhomogeneous layer, several related defects could be encountered during anodic etching. The particles between the PPFP layer and the substrate may induce local breakdown of the PPFP film leaving pinholes on the mask and micrometer-scale porous areas on the Si substrate. The PPFP film deposited on the bare silicon surface is likely to be peeled during anodic etching due to the absence of the adhesion promoter.

In order to eliminate the aforementioned side effects, a uniform adhesion promoter is certainly required. However, the optimization appears as a daunting task, because the form of plasma-polymerized $\mathrm{C}_{2} \mathrm{H}_{4}$ can be strongly affected by flow rate, pressure, RF power, and even by reactor structure. ${ }^{34}$ As aforementioned, a simple and reliable process, compatible with industry production, is needed. Hence, an unstable adhesion promoter is clearly not acceptable. For this reason, the pretreatment of silicon substrate is investigated in this work in order to obtain a surface-activated silicon substrate, which provides an alternative method to enhance adhesion strength. The PPFP synthesis is optimized by adjusting deposition parameters such as the ratio and flow rates of $\mathrm{CHF}_{3} / \mathrm{C}_{2} \mathrm{H}_{4}$, pressure, and RF power. A battery of tests (HF immersion with no bias and anodic etching) are performed to assess the quality of PPFP mask.

\section{EXPERIMENTAL}

\section{Materials}

(100)-oriented CZ single-crystalline wafers with native oxide surfaces were used. The as-received wafers were polished on one side and doped as $\mathrm{p}^{+}$type (resistivity $0.01-0.02$ $\Omega \mathrm{cm}$ ). The wafer thickness was between 493 and $523 \mu \mathrm{m}$, and the diameter was 6 in. The silicon wafers were sliced into square pieces of $3 \times 3 \mathrm{~cm}^{2}$ in size. In order to remove the possible surface contaminants, the silicon samples were first cleaned by isopropanol and then rinsed with a deionized water. Thereafter, the Si samples were dried in a nitrogen stream.

\section{Preparation of hydrogen-terminated silicon surface}

A 1:1 (in vol.) solution of $50 \mathrm{wt}$. \% hydrofluoric acid and deionized water was used for the preparation of hydrogen-terminated silicon (H-Si) surface. 2 min immersion time was sufficient to produce a uniform $\mathrm{H}-\mathrm{Si}$ surface. After being rinsed with the deionized water and dried with the nitrogen stream, the H-Si sample was immediately mounted for PPFP coating.

\section{PPFP synthesis}

Plasma polymerization, deposition on pristine (native oxide-covered) silicon and $\mathrm{H}$-Si surfaces were carried out in a reactive ion etching system (Corial 200IL). $\mathrm{CHF}_{3}$ (25-100 sccm) and $\mathrm{C}_{2} \mathrm{H}_{4}(5-25 \mathrm{sccm})$ were used as reactive monomers for plasma polymerization. A wide range of RF power

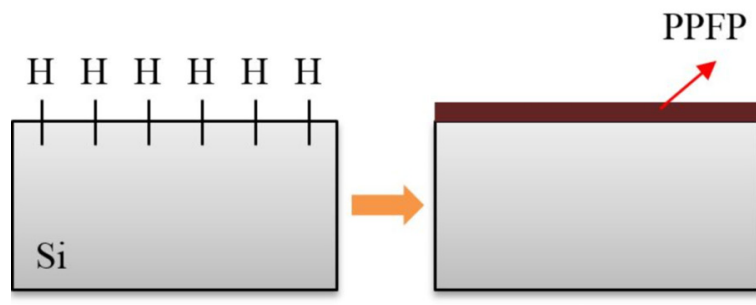

(a)

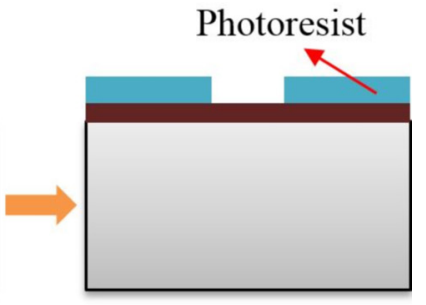

(c)

FIG. 2. Process flow of local PS formation via PPFP-based mask. (a) $\mathrm{H}-\mathrm{Si}$ surface prepared by HF etching. (b) PPFP deposition. (c) Photolithography. (d) Mask opening via $\mathrm{O}_{2}$ plasma. (e) Anodic etching. (f) Mask stripping via $\mathrm{O}_{2}$ plasma.

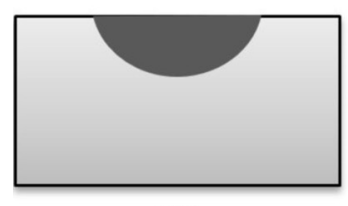

(f)

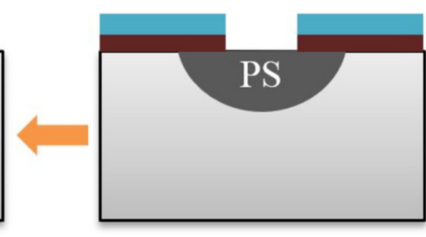

(e)

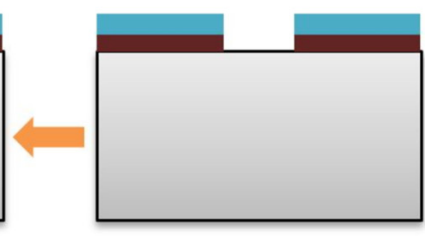

(d) 
TABLE I. Flow rate of $\mathrm{CHF}_{3}\left(\mathrm{~F}_{\mathrm{CHF} 3}\right)$, flow rate of $\mathrm{C}_{2} \mathrm{H}_{4}\left(\mathrm{~F}_{\mathrm{C} 2 \mathrm{H} 4}\right)$, measured thickness (e) of resulting PPFP film as well as the corresponding result of the HF immersion test. The rest of the deposition parameters are maintained constant; the pressure at $100 \mathrm{mTorr}$, the RF power at $100 \mathrm{~W}$, and the deposition duration at $5 \mathrm{~min}$.

\begin{tabular}{lcccc}
\hline \hline & & & Peeling time & \\
\cline { 4 - 5 } $\mathrm{F}_{\mathrm{CHF} 3}(\mathrm{sccm})$ & $\mathrm{F}_{\mathrm{C} 2 \mathrm{H} 4}(\mathrm{sccm})$ & $\mathrm{e}(\mathrm{nm})$ & Native oxide & H-Si surface \\
\hline 50 & 5 & 273 & $\sim 50 \mathrm{~s}$ & $\sim 2 \mathrm{~h}$ \\
& 10 & 286 & $\sim 6 \min 45 \mathrm{~s}$ & $>2 \mathrm{~h}$; several defects, polymer at border peeled off \\
& 15 & 278 & $\sim 25$ min & $\gg 2 \mathrm{~h}$; a few micrometer-scale defects \\
& 20 & 288 & $>2 \mathrm{~h}$; most polymer peeled off, only a few fragments left & $\gg 2 \mathrm{~h}$; a few micrometer-scale defects \\
\hline \hline
\end{tabular}

(50-200 W) and gas pressure (25-100 mTorr) were studied. The cathode temperature was controlled using back-side helium cooling and set at $20^{\circ} \mathrm{C}$ for all experiments.

\section{HF immersion test}

HF immersion test is a simple method to evaluate the adhesion of PPFP to the silicon substrate in HF-based environment. Samples fully coated by PPFP film were immersed in a $50 \mathrm{wt}$. \% HF solution during $2 \mathrm{~h}$. If a complete peelingoff was observed, the corresponding duration was noted. Otherwise, the surface morphology of the samples was examined by optical microscopy.

\section{PS patterning and anodic etching}

Fig. 2 shows the process flow of PS patterning procedures using PPFP as a mask layer. After the deposition of the PPFP thin film (cf. Fig. 2(b)), a 2.3- $\mu$ m-thick photoresist OIR 906-17 (FUJIFILM) was directly spin-coated, then followed by a standard photolithography procedure (cf. Fig. $2(\mathrm{c})$ ). The mask was then subjected to $\mathrm{O}_{2}$ plasma to locally expose silicon regions (cf. Fig. 2(d)). During this step, the FP mask etching duration was carefully monitored to fully expose the "opened" silicon regions while keeping sufficient masking material on the "blind" regions. An in-situ laser system was used to determine the endpoint of mask opening. Thereafter, the remaining photoresist and the underlying PPFP served as the mask for PS formation (cf. Fig. 2(e)). The anodic etching was carried out in a double-tank anodization cell filled with aqueous $30 \mathrm{wt}$. \% HF: $25 \mathrm{wt}$ \% $\mathrm{CH}_{3} \mathrm{COOH}$ electrolyte. Current density was maintained constant during the entire anodic etching process. Etching duration was varied from 15 to $120 \mathrm{~min}$. After anodization, the silicon samples were rinsed and then dried on a hot plate at $150^{\circ} \mathrm{C}$ in ambient air. Subsequent mask stripping was performed by $\mathrm{O}_{2}$ plasma during $2 \mathrm{~min}$ to entirely remove the masking layer (cf. Fig. 2(f)).

\section{Characterization}

The thickness of PPFP film was measured by a spectroscopic ellipsometer (SEMILAB SE-2000). Optical microscope and scanning electron microscope (SEM) were used to acquire surface morphologies and cross-sectional profiles of PS.

\section{RESULTS AND DISCUSSION}

For the application as a masking material on the silicon substrate, the deposited PPFP layer should exhibit good adhesion with the silicon substrate during electrochemical anodization in the HF-based electrolyte. In order to evaluate the behavior of polymer in HF rich environment, the method of HF immersion without bias was used to determine the effect of silicon surface chemistry. Since gas composition is the principal parameter to control the characteristic of PPFP films, the ratio of $\mathrm{CHF}_{3} / \mathrm{C}_{2} \mathrm{H}_{4}$ was primarily optimized for subsequent experiments. Afterwards, the effects of kinetic formation parameters, including gas pressure and RF power, are discussed separately.

\section{Effect of hydrogen-terminated surface}

Polymer films synthesized with various $\mathrm{CHF}_{3} / \mathrm{C}_{2} \mathrm{H}_{4}$ ratios were deposited on both native oxide-covered and $\mathrm{H}-\mathrm{Si}$ surfaces. Under equal deposition conditions, the measured thicknesses of PPFP layers via ellipsometry showed no difference between native oxide-covered and $\mathrm{H}-\mathrm{Si}$ surfaces. However, the different natures of substrate surfaces affected markedly the adhesion of polymer layer to silicon in HF solution.

Tables I and II summarize the experiment matrix and the results of $\mathrm{HF}$ immersion test. It is clear that, comparing to silicon covered with native oxide, $\mathrm{H}$-Si surface gave rise

TABLE II. Flow rate of $\mathrm{CHF}_{3}\left(\mathrm{~F}_{\mathrm{CHF} 3}\right)$, flow rate of $\mathrm{C}_{2} \mathrm{H}_{4}\left(\mathrm{~F}_{\mathrm{C} 2 \mathrm{H} 4}\right)$, measured thickness (e) of resulting PPFP film as well as the corresponding result of the HF immersion test. The rest of the deposition parameters are maintained constant; the pressure at 50 mTorr, the RF power at $150 \mathrm{~W}$, and the deposition duration at $5 \mathrm{~min}$.

\begin{tabular}{|c|c|c|c|c|}
\hline \multirow[b]{2}{*}{$\mathrm{F}_{\mathrm{CHF} 3}(\mathrm{sccm})$} & \multirow[b]{2}{*}{$\mathrm{F}_{\mathrm{C} 2 \mathrm{H} 4}(\mathrm{sccm})$} & \multirow[b]{2}{*}{ e $(n m)$} & \multicolumn{2}{|r|}{ Peeling time } \\
\hline & & & Native oxide & $\mathrm{H}-\mathrm{Si}$ surface \\
\hline 25 & 25 & 311 & $\gg 2 \mathrm{~h}$; a few micrometer-scale defects & $\gg 2 \mathrm{~h}$; no obvious defect \\
\hline 50 & & 276 & $\sim 50 \mathrm{~min}$ & $\gg 2 \mathrm{~h} ;$ no obvious defect \\
\hline 75 & & 250 & $\sim 8 \min 20 \mathrm{~s}$ & $>2 \mathrm{~h}$; a few defects at center, polymer at border slightly peeled \\
\hline 100 & & 241 & $\sim 2 \min 40 \mathrm{~s}$ & $>2 \mathrm{~h}$; several defects at center, polymer at border all peeled \\
\hline
\end{tabular}




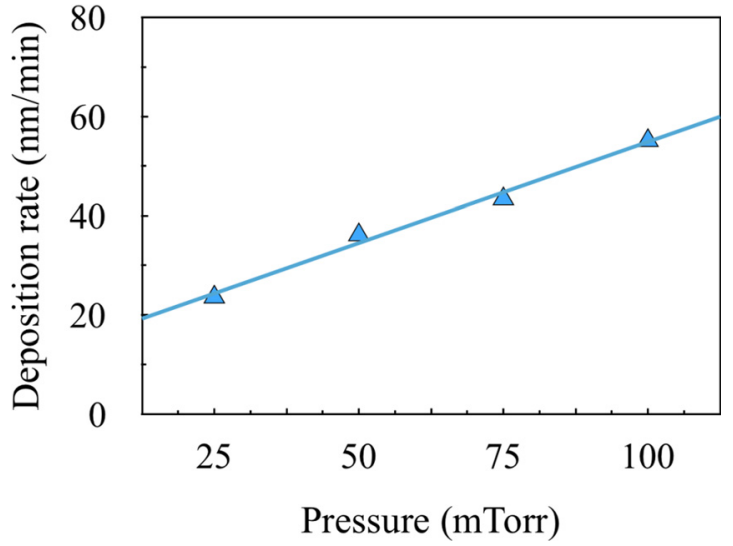

FIG. 3. Deposition rate of PPFP as a function of pressure. RF power setting is maintained at constant value $(100 \mathrm{~W})$.

to higher adhesion strength. Previous researchers have attributed this effect to the reactive nature of the dangling bonds on the $\mathrm{H}-\mathrm{Si}$ surface. ${ }^{31}$ During the plasma polymerization process, active sites can be formed on the substrate surface by scission of the $\mathrm{H}-\mathrm{Si}$ bonds via interactions with radicals and deep-UV light generated in the plasma, thereby leading to a surface-bonded polymer film.

\section{Effect of the ratio and flow rates of $\mathrm{CHF}_{3} / \mathrm{C}_{2} \mathrm{H}_{4}$}

Surprisingly, the ratio and flow rates of $\mathrm{CHF}_{3} / \mathrm{C}_{2} \mathrm{H}_{4}$ also showed remarkable influence to the adhesion strength of polymer to silicon in a HF solution. As it can be seen from Table $\mathrm{I}, \mathrm{CHF}_{3}$ was maintained at a constant flow rate $(50$ sccm) while $\mathrm{C}_{2} \mathrm{H}_{4}$ was augmented from 5 to $20 \mathrm{sccm}$. By applying $100 \mathrm{~W}$ (RF power) and $100 \mathrm{mTorr}$ (pressure), the deposition rate appears to be insensitive to the addition of $\mathrm{C}_{2} \mathrm{H}_{4}$. However, in spite of their similar thicknesses, PPFP films, deposited with various $\mathrm{CHF}_{3} / \mathrm{C}_{2} \mathrm{H}_{4}$ ratios, showed

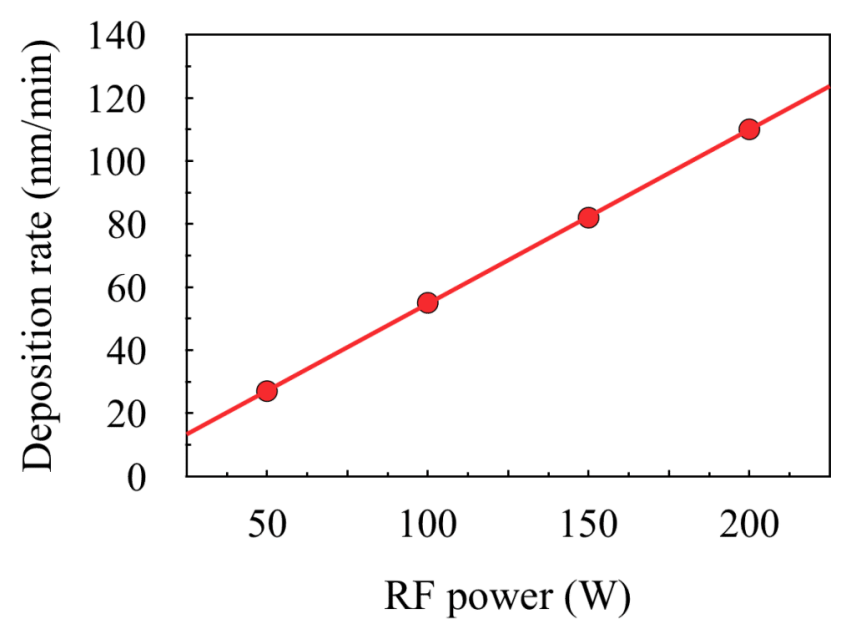

FIG. 5. Deposition rate of PPFP as a function of RF power. Pressure is maintained at constant value (100 mTorr).

different behaviors in HF solution. The differences of peeling time were emphasized when deposition was performed on native oxide-covered silicon. As indicated in Table I, for gas composition of $50 / 5 \mathrm{sccm} \mathrm{CHF}_{3} / \mathrm{C}_{2} \mathrm{H}_{4}$, the resulting polymer film delaminated very quickly from native oxidecovered silicon (less than $1 \mathrm{~min}$ ). By raising the flow rate of $\mathrm{C}_{2} \mathrm{H}_{4}$ to $20 \mathrm{sccm}$, the peeling time of polymer was more than $2 \mathrm{~h}$. Thus, the adhesion strength of PPFP film to silicon can be enhanced by increasing the addition of $\mathrm{C}_{2} \mathrm{H}_{4}$.

A similar dependence can be observed in Table II. While $\mathrm{C}_{2} \mathrm{H}_{4}$ was kept at constant flow rate $(25 \mathrm{sccm})$, by adding more $\mathrm{CHF}_{3}$ from 25 to $100 \mathrm{sccm}$, the corresponding polymer films delaminated more rapidly from silicon substrates in HF solution. As discussed above, the reduction of adhesion strength can be mainly contributed to the increased addition of $\mathrm{CHF}_{3}$ rather than the decrease of polymer thickness. Thus, the adhesion strength of PPFP film to silicon can

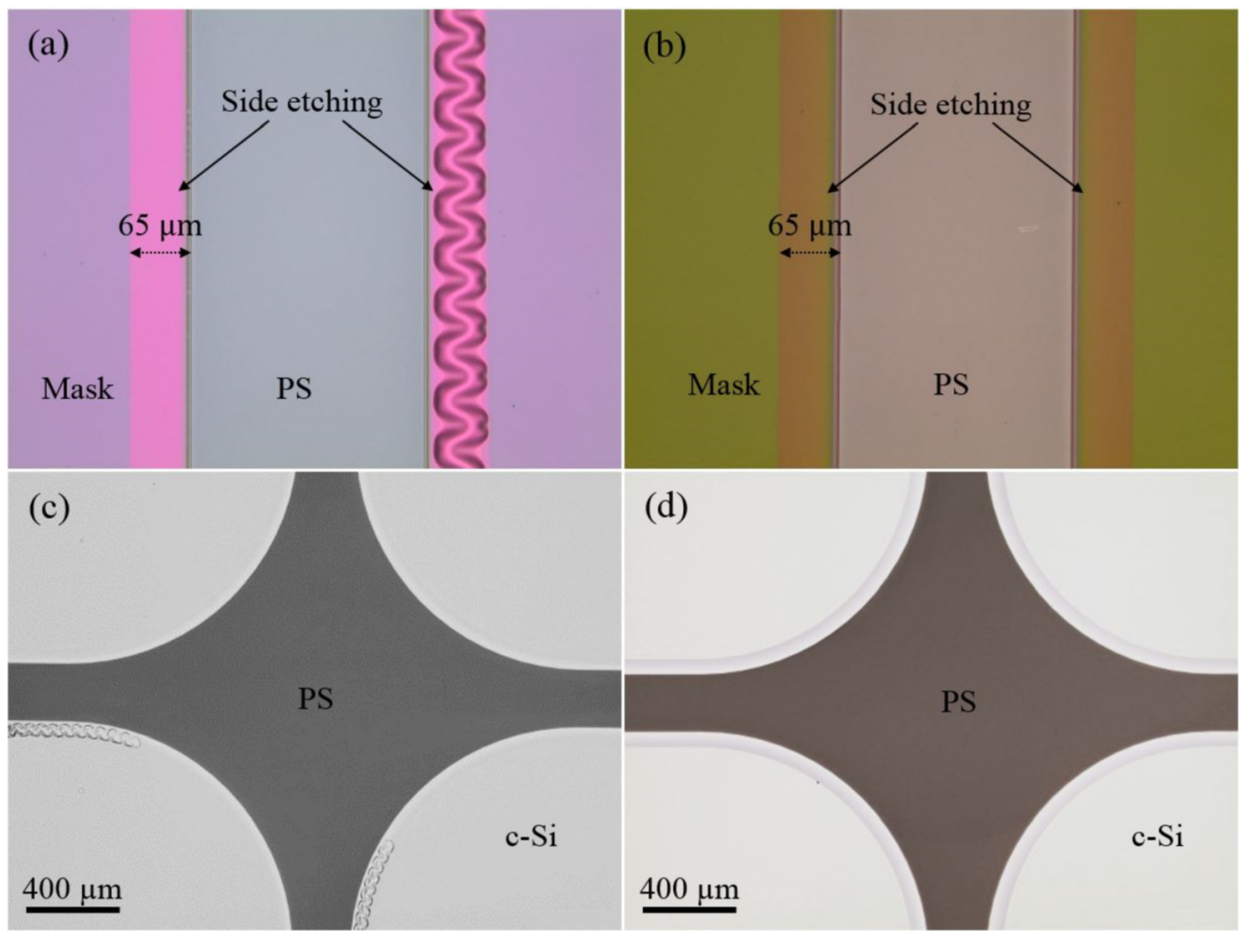

FIG. 4. Effect of pressure on PPFPbased mask: (a) and (c) 50 mTorr, (b) and (d) 100 mTorr. Anodization parameters: $45 \mathrm{~mA} / \mathrm{cm}^{2}$ current density during $1 \mathrm{~h}$. (a) and (b) are taken after anodization. (c) and (d) are taken after mask stripping. 


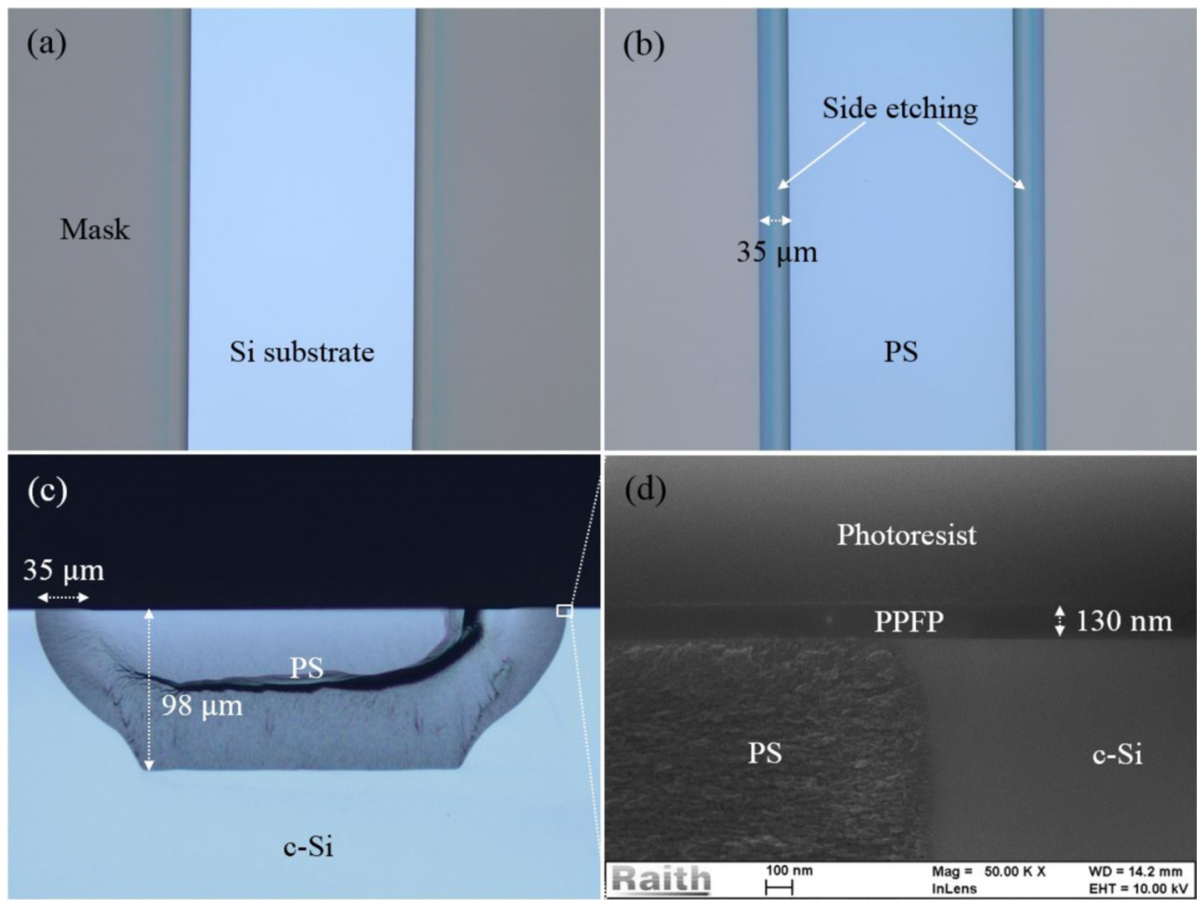

FIG. 6. Local PS formation with the PPFP-based mask. PPFP deposition parameters: $100 \mathrm{~W}$ RF power, 100 mTorr pressure, $150 \mathrm{~s}$ duration. Anodization parameters: $40 \mathrm{~mA} / \mathrm{cm}^{2}$ current density, 45 min duration. (a) and (b) Top views of the PPFP-based mask before and after anodic etching, respectively. (c) A cross-sectional view of selectively formed PS. (d) A highly magnified SEM view of a part of (c).

be enhanced by decreasing the addition of $\mathrm{CHF}_{3}$. It is noteworthy that polymer powder was likely to be formed if the flow rate of $\mathrm{CHF}_{3}$ was less than that of $\mathrm{C}_{2} \mathrm{H}_{4}$. As a consequence, the gas composition of $25 / 25 \mathrm{sccm} \mathrm{CHF}_{3} / \mathrm{C}_{2} \mathrm{H}_{4}$ seems very promising due to the formation of uniform polymeric film and the good adhesion strength of PPFP to the silicon substrate.

\section{Effect of pressure}

Pressure in the deposition chamber is an important parameter which can affect the plasma polymerization in several ways, including the distribution of active species, as well as their residence time and mean free path. ${ }^{29}$ At high pressure, due to the long residence time and short mean free path, plasma polymerization can occur more easily. In Fig. 3, it is shown that, in the range of 25-100 mTorr, polymer deposition rates increase linearly with the pressure.

In order to determine the effect of pressure on the quality of etching mask, PPFP layers deposited with two different pressure values (50 and $100 \mathrm{mTorr}$ ) were prepared for anodic etching. In Fig. 4, it was found that, after anodization, polymer deposited at a relatively low pressure resulted in "wavy edges" that randomly appeared in different positions (cf. Fig. 4(a)). After mask stripping, the form of porous area reflects this disordered border (cf. Fig. 4(c)). On the other side, the

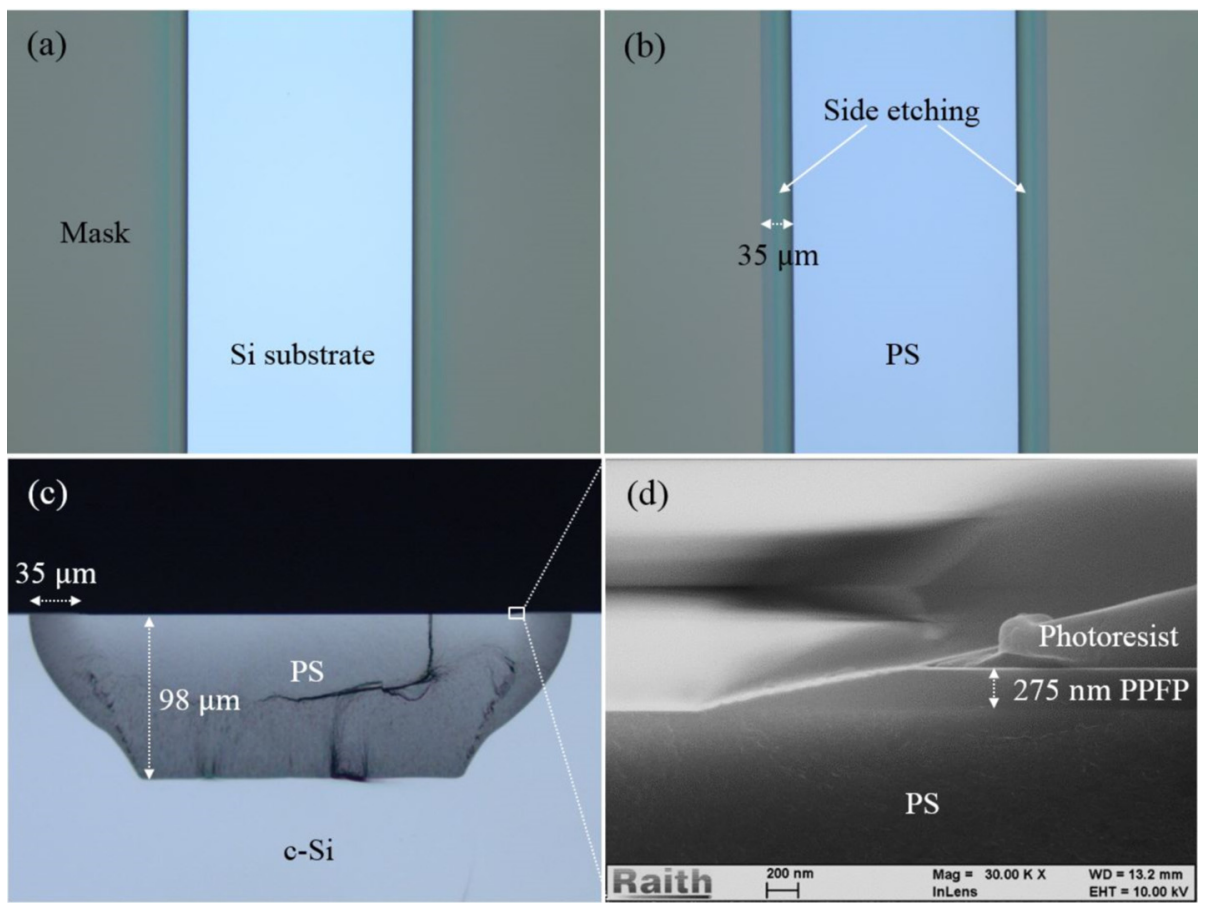

FIG. 7. Local PS formation with the PPFP-based mask. PPFP deposition parameters: $200 \mathrm{~W}$ RF power, 100 mTorr pressure, $150 \mathrm{~s}$ duration. Anodization parameters: $40 \mathrm{~mA} / \mathrm{cm}^{2}$ current density, $45 \mathrm{~min}$ duration. (a) and (b) Top views of PPFP-based mask before and after anodic etching, respectively. (c) A cross-sectional view of selectively formed PS. (d) A highly magnified SEM view of a part of (c). 
edge of PPFP mask deposited at a high pressure was well defined (cf. Fig. 4(b)). Lateral etch under mask was formed with a clear boundary (cf. Fig. 4(d)). As a result, PPFP deposited at a high pressure was selected for the application of PS mask material.

\section{Effect of power input}

Power input is another discharge parameter which affects the polymerization process. The dependence of deposition rate as a function of RF power is presented in Fig. 5. It is clear that the deposition rate is also proportional to RF power. This trend can be explained by two mechanisms.

First, in fluorocarbon plasma, there are two competing plasma-surface interactions, i.e., fluorine etching versus polymer deposition. Fluorine can react with solid surfaces (including polymer) leading to volatile etch products, while $\mathrm{CF}_{\mathrm{x}}$ radicals are responsible for polymer deposition. ${ }^{35}$ The increase in RF power directly enhances the density of all active species, including atoms, radicals, and ions. By using a $1 / 1 \mathrm{CHF}_{3} / \mathrm{C}_{2} \mathrm{H}_{4}$ ratio, the excess of $\mathrm{C}_{2} \mathrm{H}_{4}$ ensures very low density of fluorine. In this case, the concentration of etchant species is not largely affected by power rising, while the density of $\mathrm{CF}_{\mathrm{x}}$, the known polymer building block, increases markedly and therefore accelerates the polymerization process. Second, the polymer growth is believed to be triggered by charged particle bombardment. ${ }^{21}$ In the range of 50-200 W, high power value leads to an increase of self-bias potential, which promotes ionic bombardment of the surface. The polymeric surface is activated in this manner, thereby triggering the continuous growth of polymer chains.

PPFP layers deposited with two different power values were prepared for anodic etching. As shown in Figs. 6 and 7, in both cases, masked areas were well-protected. No pinhole or mask peeling-off was observed after anodic etching.

Furthermore, various etching durations were performed. The PPFP-based mask could withstand at least $2 \mathrm{~h}$ anodization duration without any pinhole formation or film peelingoff. Different thicknesses of PS layers, up to $190 \mu \mathrm{m}$, were successfully obtained. The lateral distance of under-cutting appears to be a linear function of the thickness of PS (cf. Fig. 8).

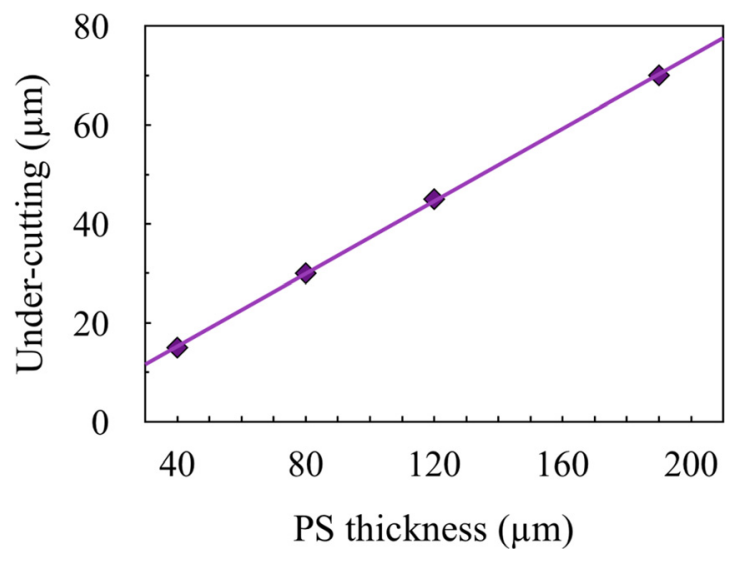

FIG. 8. Lateral under-cutting as a function of the thickness of PS.
Finally, it can be concluded that the effect of RF power seems to be limited to the deposition rate. For different power values, no obvious influence was found on polymer behavior during local PS formation.

\section{CONCLUSIONS}

This study focused on improving the adhesion strength of PPFP film to the silicon substrate without using the adhesion promoter. Five different parameters related to either silicon surface chemistry or PPFP deposition conditions were evaluated.

Our results demonstrated that, by using H-Si surface and adjusting gas composition, a good adhesion of PPFP layer to the silicon substrate could be achieved. The reactive nature of the dangling bonds on the H-Si surface gave rise to strong interaction between the polymer film and the silicon substrate. By mixing 25/25 sccm $\mathrm{CHF}_{3} / \mathrm{C}_{2} \mathrm{H}_{4}$, the adhesion of polymer film to silicon was further increased.

The investigation of two discharge parameters, pressure and RF power, revealed some linear dependencies of PPFP deposition rate. The increases in pressure and RF power both enlarge the deposition rate. For the application as a masking material, high pressure was preferred due to the smooth mask border after anodization, while RF power had no obvious influence on polymer behavior during anodic etching.

Finally, local PS formation, up to $190 \mu \mathrm{m}$ thickness, was demonstrated. Lateral etch under mask was found to be a function of the thickness of formed PS and independent of the mask thickness. Although further investigation needs to be done on wafer-scale manufacturing, the use of PPFPbased mask for the PS patterning is very attractive for industry production.

\section{ACKNOWLEDGMENTS}

This work has been performed in the frame of TOURS 2015, project supported by the French "Programme de l'économie numérique des Investissements d'Avenir."

${ }^{1}$ G. Gautier, T. Defforge, S. Desplobain, J. Billoué, M. Capelle, P. Poveda, K. Vanga, B. Lu, B. Bardet, J. Lascaud, C. Seck, A. Fèvre, S. Ménard, and L. Ventura, ECS Trans. 69, 123 (2015).

${ }^{2}$ J. Carstensen, M. Christophersen, S. Lolkes, E. Ossei-Wusu, J. Bahr, S. Langa, G. Popkirov, and H. Foll, Phys. Status Solidi C 2, 3339 (2005).

${ }^{3}$ L. Canham, Handbook of Porous Silicon (Springer, 2014).

${ }^{4}$ W. Benecke and A. Splinter, Proc. SPIE 4592, 76-87 (2001).

${ }^{5}$ S. Nagata, S. Matsushita, K. Saito, Y. Ohshita, Y. Maeda, M. Yamaguchi, and A. J. Ikushima, Appl. Phys. Lett. 82, 2559 (2003).

${ }^{6}$ S. E. Lewis, J. R. DeBoer, J. L. Gole, and P. J. Hesketh, Sens. Actuators, B Chem 110, 54 (2005).

${ }^{7}$ A. Benilov, M. Cabrera, V. Skryshevsky, and J. R. Martin, Mater. Sci. Eng. B 139, 221 (2007).

${ }^{8}$ G. Müller, A. Friedberger, and K. Knese, Handbook of Silicon Based MEMS Materials and Technologies, 1st ed. (William Andrew Publishing, 2010), p. 409.

${ }^{9}$ M. Capelle, J. Billoue, P. Poveda, and G. Gautier, Nanoscale Res. Lett. 7, 523 (2012).

${ }^{10}$ G. Gautier and P. Leduc, Appl. Phys. Rev. 1, 011101 (2014).

${ }^{11}$ M. Capelle, J. Billoue, P. Poveda, and G. Gautier, IEEE Trans. Electron Devices 62, 4169 (2015).

${ }^{12} \mathrm{~K}$. Ghenadii and C. Beongki, Porous Silicon: From Formation to Application: Formation and Properties (CRC Press, 2015), Vol. 1, p. 47.

${ }^{13}$ P. Steiner and W. Lang, Thin Solid Films 255, 52 (1995). 
${ }^{14}$ Y. Tao and M. Esashi, J. Micromech. Microeng. 14, 1411 (2004).

${ }^{15}$ H. Wang, B. Welker, Y. Gao, J. F. Federici, and R. A. Levy, Mater. Lett. 23, 209 (1995).

${ }^{16}$ M. Krüger, R. Arens-Fischer, M. Thönissen, H. Münder, M. G. Berger, H. Lüth, S. Hilbrich, and W. Theiss, Thin Solid Films 276, 257 (1996).

${ }^{17}$ M. K. Lee, C. C. Hu, and Y. H. Wang, Jpn. J. Appl. Phys. 35, L865 (1996).

${ }^{18}$ G. Kaltsas and A. G. Nassiopoulou, Sens. Actuators, A 65, 175 (1998).

${ }^{19}$ L. S. Swanson and D. A. Prinslow, U.S. patent 6,103,590 (15 August 2000).

${ }^{20}$ E. Galeazzo, W. J. Salcedo, H. E. M. Peres, and F. J. Ramirez-Fernandez, Sens. Actuators, B 76, 343 (2001).

${ }^{21}$ J. D. L. Shapley and D. A. Barrow, Thin Solid Films 388, 134 (2001).

${ }^{22}$ A. Splinter, O. Bartels, and W. Benecke, Sens. Actuators, B 76, 354 (2001).

${ }^{23}$ T. Djenizian, L. Santinacci, H. Hildebrand, and P. Schmuki, Surf. Sci. 524, 40 (2003).

${ }^{24}$ H. S. Kim, K. Chong, and Y. H. Xie, Appl. Phys. Lett. 83, 2710 (2003).

${ }^{25}$ V. V. Starkov, E. Y. Gavrilin, J. Konle, H. Presting, A. F. Vyatkin, and U. Konig, Phys. Status Solidi A 197, 150 (2003).
${ }^{26}$ M. K. Oisten and P. L. Bergstrom, Phys. Status Solidi C 6, 1541 (2009).

${ }^{27}$ T. Defforge, M. Capelle, F. Tran-Van, and G. Gautier, Nanoscale Res. Lett. 7, 344 (2012).

${ }^{28}$ E. Hourdakis and A. G. Nassiopoulou, J. Micromech. Microeng. 24, 117002 (2014).

${ }^{29}$ R. d'Agostino, F. Cramarossa, F. Fracassi, and F. Illuzzi, Plasma Deposition, Treatment, and Etching of Polymers (Academic Press, San Diego, 1990), p. 95.

${ }^{30}$ Y. Zhang, K. L. Tan, B. Y. Liaw, D. J. Liaw, E. T. Kang, and K. G. Neoh, Langmuir 17, 2265 (2001).

${ }^{31}$ G. D. Fu, E. T. Kang, and K. G. Neoh, J. Phys. Chem. B 107, 13902 (2003).

${ }^{32}$ J. Zhang, C. Q. Cui, T. B. Lim, E.-T. Kang, K. G. Neoh, S. L. Lim, and K. L. Tan, Chem. Mater. 11, 1061 (1999).

${ }^{33}$ M. Niinomi, H. Kobayashi, A. T. Bell, and M. Shen, J. Appl. Phys. 44, 4317 (1973).

${ }^{34}$ H. Kobayashi, M. Shen, and A. T. Bell, J. Macromol. Sci. Chem. 8, 373 (1974).

${ }^{35}$ V. Yanev, S. Krischok, A. Opitz, H. Wurmus, J. A. Schaefer, N. Schwesinger, and S. I. U. Ahmed, Surf. Sci. 566-568(Part 2), 1229 (2004). 